\title{
Continuation of a Levonorgestrel Intrauterine Device During Hematopoietic Stem Cell Transplant: A Case Report
}

\author{
PAULA C. BRADY ${ }^{1}$, ROBERT J. SOIFFER ${ }^{2}$ and ELIZABETH S. GINSBURG ${ }^{1}$ \\ ${ }^{1}$ Department of Obstetrics, Gynecology and Reproductive Biology, \\ Brigham and Women's Hospital, Harvard Medical School, Boston, MA, U.S.A.; \\ ${ }^{2}$ Dana-Farber Cancer Institute and Brigham and Women's Hospital, Harvard Medical School, Boston, MA, U.S.A.
}

\begin{abstract}
Background: During treatment of hematologic malignancies in premenopausal women, both menstrual suppression and contraception are crucial. Continuation of hormonal intrauterine devices (IUDs) - widely used and highly effective contraceptives that also decrease menstrual flow - is controversial during hematopoietic stem cell transplants (SCTS) due to infectious and vaginal bleeding concerns. Case Report: A 23-year-old nulligravid female was diagnosed with acute myeloid leukemia (AML, positive for FLT3-ITD, DNMT3A and RUNX1, with normal cytogenetics). She elected to retain her existing levonorgestrel-containing IUD during chemotherapy and SCT. During and following treatment, she remained amenorrheic without infection, despite severe neutropenia and thrombocytopenia. Eight months later, she remains in remission without IUD-related complications. Discussion: This is the first report of levonorgestrel IUD retention during hematopoietic SCT. Despite severe neutropenia and thrombocytopenia, the patient developed neither pelvic infection by retaining her IUD nor significant vaginal bleeding. Future studies are needed to confirm the safety of levonorgestrel IUDs in women undergoing SCT.
\end{abstract}

Approximately 83 per 100,000 women under the age of 50 years are diagnosed with hematologic malignancies in the United States each year (1). Many of these women will develop thrombocytopenia as a result of their illness or treatment, requiring menstrual suppression to prevent vaginal

Correspondence to: Paula C. Brady, MD, Department of Obstetrics, Gynecology and Reproductive Biology, Brigham and Women's Hospital, Harvard Medical School, 75 Francis St., ASBI-3, Boston, MA 02115, U.S.A. Tel: +1 6177324648, Fax: +1 6175667752, e-mail: pbrady2@partners.org

Key Words: Acute myeloid leukemia, oncofertility, contraception, intrauterine device, IUD, levonorgestrel, menstrual suppression, chemotherapy, hematopoietic stem cell transplant. hemorrhage; contraception is also a vital part of gynecologic care in all premenopausal women, including cancer patients.

Intrauterine devices (IUDs) are currently utilized by approximately $14 \%$ of reproductive-age women worldwide and 5\% women in the United States $(2,3)$. IUDs are a highly effective form of contraception, with failure in less than $1 \%$ of women (4). In patients without cancer, levonorgestrel IUDs are also reported to induce significant reduction in menstrual blood loss, with amenorrhea occurring in up to one-third of patients (5).

Continuation (but not insertion) of levonorgestrel IUDs in immunocompromised patients is supported by the Centers for Disease Control and American College of Obstetricians and Gynecologists, using data extrapolated from patients with human immunodeficiency virus (HIV) and solid-organ transplants (6-8). Hematopoietic stem cell transplants (SCTs), however, are distinct from these other immunosuppressive conditions due to myeloablative treatment prior to transplant; in addition to the risk of vaginal bleeding due to thrombocytopenia, these patients are at the highest risk of infection due to lack of immune function.

Earlier versions of IUDs were associated with increased risk of infection, likely due to braided IUD strings; contemporary IUDs, including the Mirena ${ }^{\circledR}$ IUD (Bayer, Whippany, NJ, USA), carry a low risk of infection $(<1 \%)$, which is highest in the first 20 days following insertion (9, 10). In fact, levonorgestrel IUDs are associated with an overall decreased risk of upper genital tract infections, likely related to progestin-mediated effects (11).

In patients undergoing hematopoietic stem cell transplantation, no data have been published regarding continuation of levonorgestrel IUDs for menstrual suppression and the theoretical risk of infection of these indwelling foreign bodies.

\section{Case Report}

The patient was a 23-year-old nulligravid woman with a history of treated Graves disease and a mood disorder, who presented 
with severe epistaxis. Her absolute neutrophil count was $1.0 \times 10^{3} / \mu \mathrm{l}$ with $61 \%$ lymphoblasts; her platelets were $19,000 / \mu 1$. Flow cytometry of peripheral blood was consistent with acute myeloid leukemia (AML). Bone marrow aspiration (both morphological examination and flow cytometry) confirmed the diagnosis of AML; further studies showed positivity for FLT3-ITD, DNMT3A and RUNX1 mutations and normal cytogenetics. Reproductive endocrinology was consulted for menstrual suppression and potential fertility preservation. The patient reported that she had a Mirena ${ }^{\circledR}$ IUD in place, which had been placed one month prior to presentation for contraception and due to her dissatisfaction with persistent irregular spotting while on oral contraceptive pills. She reported scant ongoing vaginal spotting since IUD insertion.

Following counseling regarding options for menstrual suppression, the decision was made with the patient to retain her IUD, as her vaginal bleeding was well-controlled and removing the IUD might cause further bleeding in the setting of severe pancytopenia. She was satisfied with her IUD and preferred to maintain it. She also elected to receive intramuscular leuprolide acetate $11.25 \mathrm{mg}$ for both additional menstrual suppression and hoped for fertility preservation, extrapolated from the breast cancer literature (12). As laboratory values (estradiol $32 \mathrm{pg} / \mathrm{ml}$ and progesterone $0.92 \mathrm{ng} / \mathrm{ml}$ ) indicated that the patient was in the follicular phase of the menstrual cycle, in order to avoid a flare effect, she received oral contraceptive pills (norethindrone $1 \mathrm{mg}$, ethinyl estradiol $0.035 \mathrm{mg}$ ) twice per day for three days prior to administration of leuprolide acetate. Oral contraceptive pills were continued daily for an additional week following administration of leuprolide acetate to address a moderate increase in bleeding, which resolved.

The patient received induction chemotherapy with doxorubicin, cytarabine and crenolanib, an investigational FLT3 inhibitor (AROG Pharmaceuticals, Dallas, TX, USA). Following induction chemotherapy and recovery of hematopoetic function, eight weeks after diagnosis, the antimullerian hormone level was $2.9 \mathrm{ng} / \mathrm{ml}$; the patient underwent controlled ovarian hyperstimulation using a gonadotropinreleasing hormone antagonist protocol, with five oocytes retrieved. The patient subsequently received consolidation chemotherapy with cytarabine and continued crenolanib. She continued to have menses after these two courses of chemotherapy.

She was re-admitted two months later, five months after initial diagnosis, for conditioning chemotherapy with fludarabine and busulfan, as well as hematopoietic stem cell transplantation. She received cyclophosphamide after transplant. As predicted, the patient was severely neutropenic during her course and required transfusions, with a platelet nadir of $9,000 / \mu \mathrm{l}$ and hematocrit nadir of $22.4 \%$. Her course was complicated by severe mucositis and nausea, but she did not develop vaginal bleeding after admission for transplant.
The patient's last computed tomographic scan, obtained during her stem cell transplant, confirmed that the IUD remained appropriately positioned. In the months following her hematopoietic stem cell transplant, the patient had thrombocytopenia (to a nadir of $13,000 / \mu 1$ ) attributed to idiopathic thrombocytopenia, which improved with prednisone. Repeat bone marrow aspiration has confirmed continued remission; her IUD remains in place with no evidence of infection.

\section{Discussion}

This is the first report of leaving a levonorgestrel intrauterine device in place during hematopoietic stem cell transplantation. Despite severe neutropenia and thrombocytopenia, the patient developed neither pelvic infection by retaining her IUD nor significant vaginal bleeding. During her conditioning chemotherapy and stem cell transplant, she was no longer within the therapeutic window of her 3-month depot leuprolide acetate injection given five months prior and her vaginal bleeding was presumably solely controlled by her IUD.

The existing literature is extremely sparse concerning IUD retention in oncologic patients. A survey of 107 reproductive-age patients diagnosed with cancer within 5 years (including 9 patients with leukemia) reported that $4 \%$ retained their IUDs during cancer treatment (13). Which patients retained their IUDs, the type of IUD and the nature of the patients' oncologic treatment were not reported. IUD migration and perforation has been reported in a young woman following treatment with bevacizumab (a vascular endothelial growth factor inhibitor) for colon cancer; the IUD was removed without issue (14). Authors theorized that this perforation may have been related to the pathophysiology of spontaneous bowel perforations specifically associated with bevacizumab.

As compared to the general oncology population, patients undergoing hematopoietic stem cell transplant carry a distinctly high risk for infection due to their significant myelosuppression and many clinicians are hesitant to leave an IUD in situ due to this risk. This is the first report of continuation of a levonorgestrel intrauterine device during hematopoietic stem cell transplantation, with effective menstrual suppression and without pelvic infection despite severe neutropenia. This case suggests that levonorgestrel IUDs do not necessarily need to be removed before SCT due to concern for pelvic infection. The role of non-hormonal IUDs, such as the copper-based ParaGard ${ }^{\circledR}$ IUD (Teva Women's Health, North Wales, PA, USA), in these patients is unclear, particularly as non-hormonal IUDs are often associated with heavier menses, even in patients without hematologic abnormalities. Larger, future studies are needed to confirm the efficacy of levonorgestrel IUDs for menstrual 
suppression and their safety in women undergoing myeloablation (including those receiving whole body radiation, which this patient did not undergo) followed by hematopoietic stem cell transplant.

\section{Sources of Funding/Support}

None.

\section{References}

1 NCI FastStats: Statistics stratified by age. Surveillance Epidemiology and End Results (SEER). [online] 2009-2013. http://seer.cancer.gov/faststats. Accessed September 27, 2016.

2 Buhling KJ, Zite NB, Lotke P, Black K and INTRA Writing Group: Worldwide use of intrauterine contraception: a review. Contraception 89: 592-598, 2014.

3 United Nations: World Contraceptive Use 2015. http:// www.un.org/en/development/desa/population/publications/datase t/contraception/wcu2015.shtml. Accessed September 18, 2016.

4 World Health Organization/Department of Reproductive Health and Research (WHO/RHR); Johns Hopkins Bloomberg School of Public Health (JHSPH)/Center for Communication Programs (CCP): Family planning: A global handbook for providers. Baltimore (MD): CCP; 2007. Co-published by WHO https://www.fphandbook.org/ Accessed September 17, 2016.

5 Irvine GA, Campbell-Brown MB, Lumsden MA, Heikkila A, Walker JJ and Cameron IT: Randomised comparative trial of the levonorgestrel intrauterine system and norethisterone for treatment of idiopathic menorrhagia. Br J Obstet Gynaecol 105: 592-598, 1998.

6 Browne $\mathrm{H}$, Manipalviratn $\mathrm{S}$ and Armstrong A: Using an intrauterine device in immunocompromised women. Obstet Gynecol 112: 667-669, 2008.

7 Centers for Disease Control and Prevention (CDC): U.S. medical eligibility criteria for contraceptive use, 2010. MMWR Recomm Rep 59: 1-86, 2010.
8 American College of Obstetrics and Gynecology: Committee opinion no. 606: Options for prevention and management of heavy menstrual bleeding in adolescent patients undergoing cancer treatment. Obstet Gynecol 124: 397-402, 2014.

9 Birgisson NE, Zhao Q, Secura GM, Madden T and Peipert JF: Positive testing for neisseria gonorrhoeae and chlamydia trachomatis and the risk of pelvic inflammatory disease in IUD users. J Womens Health (Larchmt) 24: 354-359, 2015.

10 Farley TM, Rosenberg MJ, Rowe PJ, Chen JH and Meirik O: Intrauterine devices and pelvic inflammatory disease. Lancet 339: 785-788, 1992.

11 Toivonen J: Intrauterine contraceptive device and pelvic inflammatory disease. Ann Med 25: 171-173, 1993.

12 Moore HC, Unger JM, Phillips KA, Boyle F, Hitre E, Porter D, Francis PA, Goldstein LJ, Gomez HL, Vallejos CS, Partridge AH, Dakhil SR, Garcia AA, Gralow J, Lombard JM, Forbes JF, Martino S, Barlow WE, Fabian CJ, Minasian L, Meyskens FL $\mathrm{Jr}$, Gelber RD, Hortobagyi GN, Albain KS and POEMS/S0230 Investigators: Goserelin for ovarian protection during breastcancer adjuvant chemotherapy. N Engl J Med 372: 923-932, 2015.

13 Maslow BS, Morse CB, Schanne A, Loren A, Domchek SM and Gracia CR: Contraceptive use and the role of contraceptive counseling in reproductive-aged women with cancer. Contraception 90: 79-85, 2014.

14 Uguen T, Leconte B, Desgrippes R, Tchoundeu B, Bretagne JF and Manfredi S: First description of a uterine perforation potentially imputable to treatment with bevacizumab. Acta Oncol 51: 1102-1104, 2012.
Received February 2, 2017

Revised March 10, 2017

Accepted March 13, 2017 